\title{
Smart Voltage-Source Inverters with a Novel Approach to Enhance Neutral-Current Compensation
}

\author{
Fida Hasan Md Rafi, M. J. Hossain, Senior Member, IEEE, G. Town, Senior Member, IEEE and J. Lu, Senior Member, IEEE
}

\begin{abstract}
The presence of a neutral current is quite common in three-phase (3P) four-wire $(4 \mathrm{~W})$ distribution systems due to an unequal distribution of linear and nonlinear single-phase (1P) loads and small distributed generators. However, a high neutral current can overload the neutral conductor and distribution transformer, which can cause electrical safety concerns and even fire. Among several existing neutral current compensators, the 3P four-leg (4L) voltage-source inverter (VSI) provides better control flexibility and more efficient performance than the passive compensators but requires a higher VSI capacity for the fourth-leg operation. To provide a solution to the aforementioned problem, this paper presents a novel control method to utilize the available capacity of a 3P-4L VSI after active and reactive power regulation to enhance the neutral-current compensation. A smart (S) VSI is designed to operate with a solar photovoltaic (PV) unit, regulate the ac side voltage and minimise the neutral current. Case studies are conducted with actual load data from a commercial building in the PSCAD/EMTDC software environment. The designed system with the proposed control method can provide a significant improvement in the neutral-current compensation, phase balancing and unbalance factor compared to a fixed-capacity 3P-4L SVSI. Experimental results using a TMS320F28335 digital signal processor microcontroller and modified Semiteach 3P-4L inverter are presented to verify the robustness of the designed controller and the enhancement to the neutral-current compensation using the proposed dynamic capacity-control method.
\end{abstract}

Index Terms- Neutral current, 3P-4L SVSI, 3P-4W network, LV network, commercial load.

\section{INTRODUCTION}

$\mathrm{I}_{\mathrm{N}}^{\mathrm{N}}$ NFORMATION technology (IT) is making the world step into the digital domain, where appliances based on electronic devices and computer technology are dominating in every sector. Most of these appliances are single-phase (1P) loads which are commonly supplied by a three-phase (3P) delta-wye $(\Delta-Y)$-configured distribution transformer (DT) in residential and commercial distribution networks (DNs). The neutral line, which is supplied from the Y common terminal of the DT, is used to install both three- and single-phase loads in a three-phase fourwire $(3 \mathrm{P}-4 \mathrm{~W}) \mathrm{DN}$. It acts as a reference point for the loads and is commonly designed to carry ground-fault and leakage currents. With the increase in unequal distribution of linear and nonlinear 1P loads, the neutral conductor is forced to carry a larger neutral current, resulting in an energy loss, by overheating the DT [1], overloading the neutral conductor [2], malfunction of sensitive equipment, power-line communication interference [3], electrical safety concerns, and even fire [4].

One simple solution is to distribute the loads equally in all three phases, however, this is not possible in practice for large networks. Therefore, different unbalance-compensation devices, such as magnetic transformers like zigzag, star-delta, and T- shape [5], power-redistribution devices [6], 1P compensators with matching transformers [7], 3P-4W active-power filters (APF), such as a split-dc link [8], three H-bridge [9], and 3P fourleg (4L) converters [10], are installed to provide control over the neutral current along with active and reactive power regulation. The magnetic-core transformers and $3 \mathrm{P}-4 \mathrm{~W}$ converters provide passive unbalance compensation with indirect control over neutral current. On the other hand, $1 \mathrm{P}$ and $3 \mathrm{P}-4 \mathrm{~L}$ converters can provide direct control over neutral current and better unbalance compensation than the indirect control solutions.

Among the active compensators, the $1 \mathrm{P}$ converter, which is installed directly at the neutral line, requires a magnetic core transformer for grid connection, and the 3P-4L compensator, which controls the neutral current using a half-bridge switching module, requires a higher converter capacity because of higherpower switching devices. Considering the trade-offs among the unbalance compensators, the $3 \mathrm{P}-4 \mathrm{~L}$ converter can provide multifunctions via controlling active, reactive and neutral currents from a single system. The $3 \mathrm{P}-4 \mathrm{~L}$ can provide better voltage regulation, harmonic and neutral-current compensation than the $\Delta$-Y transformer and a split dc-bus converter as presented for a stand-alone double-fed induction generator system in [11]. A 3P-4L smart voltage-source inverter (SVSI) is designed with optimal functionality under various network contingencies and with residential loads in [10]. However, the higher capacity requirement problem remained unanswered.

A resonant controller for a $3 \mathrm{P}-4 \mathrm{~L}$ APF is controlled using conservative power theory (CPT) to improve the stability and power quality of microgrids in [12]. The residual capacity of the APF is shared among neighbors to compensate for unbalanced currents and reduce the rating of the APFs. However, an estimation of the residual capacity is not presented, and the communication requirements can increase the control delay. in the system. CPT is applied to a grid-tied 3P-4L converter for wind turbines to mitigate the load-current unbalances and improve the power quality in [13]. Similarly, the 3P-4L converter is utilized for leakage current elimination from photovoltaic (PV) installations in [14]. Despite many applications of 3P-4L converters in unbalance compensation, none of the papers in the literature present how the higher capacity requirement can be met. Generally, for the 3P-3W low voltage (LV) distribution system, the VSI capacity is utilized for active and reactive power operation [15]. In [16], the authors present dynamically varying limits with positive and negative sequence current controllers in an unbalanced microgrid to protect the VSI from overloading during system faults and severe unbalance conditions. However, a fixed hard limit with the zero-sequence current controller is used to avoid complexity. For 3P-4W systems, the authors in [1] and [17] show that the total capacity of a VSI can be expressed 
as the combination of active, reactive and unbalanced current components. Using this theory, an enhanced neutral-current compensation method is proposed and utilized with a $3 \mathrm{P}-4 \mathrm{~L}$ SVSI.

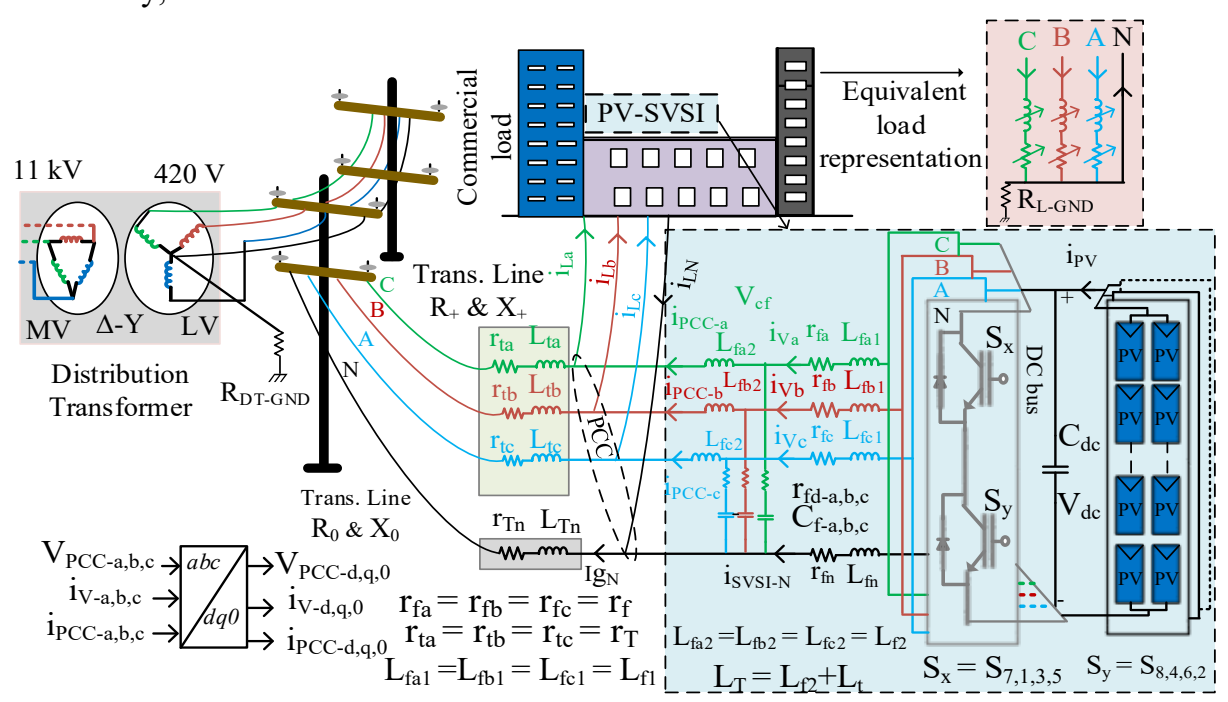

Figure 1. PV-SVSI connection with commercial loads and LV network.

The 3P-4L SVSI is designed to provide independent control over active, reactive and neutral currents. The current controllers are integrated with saturation limiters (SLs) with dynamic current limits which update their values depending on the control requirements. Any available capacity of the SVSI after active power regulation is first allocated for reactive-current and then for neutral-current control. The SL in the neutral-current controller is selected as the summation of fixed and dynamic current limits. The remaining capacity after active and reactive power regulation is added as a dynamic current limit to the neutral-current controller, thereby providing a higher-capacity unbalance compensation from the designed system.

The contributions of this paper are: (i) developing the relationship of the available capacity of an SVSI based on active, reactive and unbalance powers, and (ii) utilizing the unused capacity of an SVSI after active and reactive current controls to enhance neutral-current compensation using dynamic saturation current limiters in a 3P-4L SVSI. The 3P-4L SVSI with the proposed control method is designed for a PV system and implemented in PSCAD/EMTDC software utilizing real solar irradiance and load data from a commercial building. It also presents experimental verification from a modified Semikron Semiteach 3P-4L inverter and real-time digital signal processor (DSP) microcontroller (TMS320F28335). Both simulation and experimental results are compared with a commonly used fixedcapacity 3P-4L SVSI compensator $[10,16]$, and the results prove that the proposed control method provides better neutral-current compensation, phase balancing and power-quality improvement whilst also regulating the active and reactive powers.

The organization of the remainder of this paper is as follows: Section II describes the system design and proposed control method; stability analysis of the designed controller is presented in Section III, and in Section IV, the designed system performance from both simulation and experimental results is presented. The paper then concludes mentioning future studies in Section V.

\section{SYSTEM CONFIGURATION AND PROPOSED CONTROL METHOD}

The 3P-4L SVSI system is designed as a single-stage transformerless configuration with a PV system, an LCL filter, commercial loads, and grid connections as shown in Fig. 1.

A dc voltage regulator is used to regulate a constant dc bus voltage across the dc-link capacitor irrespective of the current control operations. The SVSI is connected to the grid via an LCL filter and an L filter in the fourth leg. The commercial loads are represented as a 1P R-L combination as shown in Fig. 1, and actual load consumption data from a university building is applied in the continuously varying load model. The load is considered to be connected in a TT (Terra-Terra) LV network. The power distribution lines are represented as series R-L combinations for all four wires. The phase lines are represented with positive-sequence parameters $\left(\mathrm{R}_{+}\right.$and $\left.\mathrm{X}_{+}\right)$[10], [18], and the neutral wire with zero-sequence parameters $\left(\mathrm{R}_{0}\right.$ and $\left.\mathrm{X}_{0}\right)$ of the transmission line conductors as shown in Fig. 1. As the variation in the positive- and zero-sequence parameters of different transmission (trans.) line conductors has a significant effect on active, reactive and neutral current controls, the SVSI is designed to provide independent and stable control of active, reactive and neutral currents irrespective of contingencies from any network, load or power sources. The designed SVSI system can be mathematically represented as [10]:

$$
\begin{aligned}
& \frac{d}{d t} i_{V(d, q)}=\frac{V_{d c}}{L_{f 1}} d_{d, q}-\frac{r_{f}}{L_{f 1}} i_{V(d, q)}-\frac{r_{f d}}{L_{f 1}}\left(i_{V(d, q)}-i_{P C C-(d, q)}\right)- \\
& \frac{V_{c f(d, q)}}{L_{f 1}} \pm \omega i_{V(q, d)} \\
& \frac{d}{d t} i_{P C C-(d, q)}=\frac{V_{c f(d, q)}}{L_{T}}-\frac{r_{T}}{L_{T}} i_{P C C-(d, q)}+\frac{r_{f d}}{L_{T}}\left(i_{V(d, q)}-i_{P C C-(d, q)}\right)- \\
& \frac{V_{P C C(d, q)}}{L_{T}} \pm \omega i_{P C C-(q, d)} \\
& \frac{d}{d t} V_{c f(d, q)}=\frac{i_{V(d, q)}}{C_{f}}-\frac{i_{P C C-(d, q)}}{C_{f}} \mp \omega V_{c f(q, d)} \\
& \frac{d}{d t} V_{d c}=\frac{i_{p v}}{C_{d c}}-\frac{\sum i_{V(d, q, 0)} d_{d, q, 0}}{C_{d c}} \\
& \frac{d}{d t} i_{V 0}=\frac{1}{L_{f 1}+3 L_{f n}} V_{d c} d_{0}-\frac{r_{f}+3 r_{f n}}{L_{f 1}+3 L_{f n}} i_{V 0}-\frac{r_{f d}}{L_{f 1}+3 L_{f n}}\left(i_{V 0}-i_{P C C-0}\right)- \\
& \frac{V_{c f(0)}}{L_{f 1}+3 L_{f n}}
\end{aligned}
$$


$\frac{d}{d t} i_{P C C-0}=\frac{1}{L_{T}+3 L_{T n}} V_{c f(0)}-\frac{r_{T}+3 r_{T n}}{L_{T}+3 L_{T n}} i_{P C C-0}+\frac{r_{f d}}{L_{T}+3 L_{T n}}\left(i_{v 0}-\right.$

$\left.i_{P C C-0}\right)-\frac{V_{P C C(0)}}{L_{T}+3 L_{T n}}$

$\frac{d}{d t} V_{c f 0}=\frac{i_{V 0}}{C_{f}}-\frac{i_{P C C-0}}{C_{f}}$

$i_{S V S I-N}=-3 i_{V 0}$

where the ' $V$ ', ' $f$ ', ' $P C C$ ', and ' $T$ ' subscripts represent SVSI, filter, point of common coupling and transmission lines respectively, and other symbols carry their standard meanings [10]. The overall control design is based on the popularly used synchronously rotating frame (SRF) theory, which transforms the actual ac signals, i.e. voltages and currents, from the system to equivalent dc quantities ( $d$ and $q$ ). The relationship for the zero-sequence and neutral-current components are presented in (8), and it is evident that controlling any one of the currents can have a direct effect on the others. It is also evident that the neutral and zero sequence quantities do not have any coupling terms with the $d$ and $q$ current components. A passive damping resistor, $R_{d}$, is used with the LCL filter to improve the damping of the LV grid network. Based on the expressions from (1)-(8), four current control loops $(\mathrm{CC})$ using proportional-integral (PI) controllers are designed: (i) active $\left(I_{d}\right)$, (ii) reactive $\left(I_{q}\right)$, (iii) neutral $\left(I_{N}\right)$ and (iv) zero sequence $\left(I_{0}\right)$. The reference for the control loops can be manually calculated based on power ratings or can be autonomously selected via external control loops. Two external voltage regulators, i.e. (i) dc bus voltage, and (ii) point of common coupling (PCC) ac voltage, are used to generate the references for the active- and reactive-current controllers respectively. The load-generated neutral current is applied as a direct reference to the neutral current controller and, following (8), the zero-sequence current-controller reference is generated. The overall control diagram with a decoupled current controller and the sinusoidal pulse-width-modulation (SPWM) process are shown in Fig. 2.

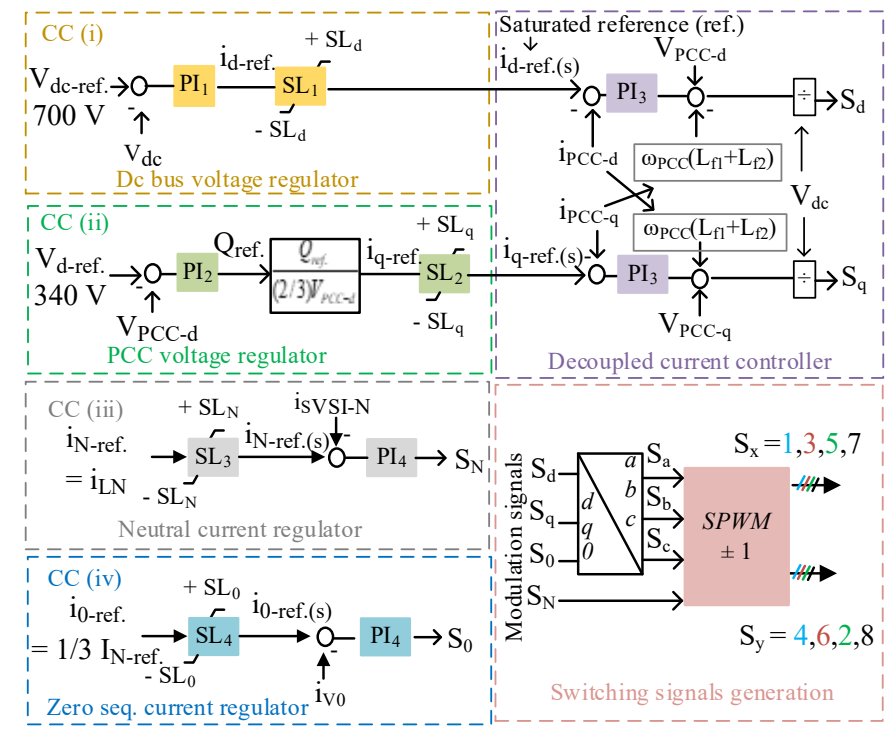

Figure 2. 3P-4L SVSI control diagram.

It can be seen from Fig. 2 that each of the current controllers is integrated with a saturation limiter (SL). Based on the control requirements, the values of the upper $(+)$ and lower $(-)$ limits of SL will be changed following the expressions derived from the proposed capacity-control method as shown in Fig. 3. The total capacity of the 3P-4L SVSI can be represented as [1], [17]:

$$
S_{S V S I}=\sqrt{D_{u}^{2}+\left(P_{V S I}^{2}+Q_{V S I}^{2}\right)}
$$

where $D_{u}, S_{V S I}, P_{V S I}$, and $Q_{V S I}$ are the unbalance, apparent, active and reactive powers of the SVSI respectively. It can be seen from Fig. 3 that the total VSI capacity is initially dedicated to the active power regulation, and the $( \pm) \mathrm{SL}_{d}$ is generated for CC (i) in step 1. The $( \pm) \mathrm{SL}_{\mathrm{q}}$ is generated for $\mathrm{CC}$ (ii) based on the remaining VSI capacity after the CC (i) execution in step 2. Whilst additional capacity could be used for reactive power compensation, it is not included in this paper. For the neutral current controller, two types of capacity are considered, (i) fixed, and (ii) dynamic.

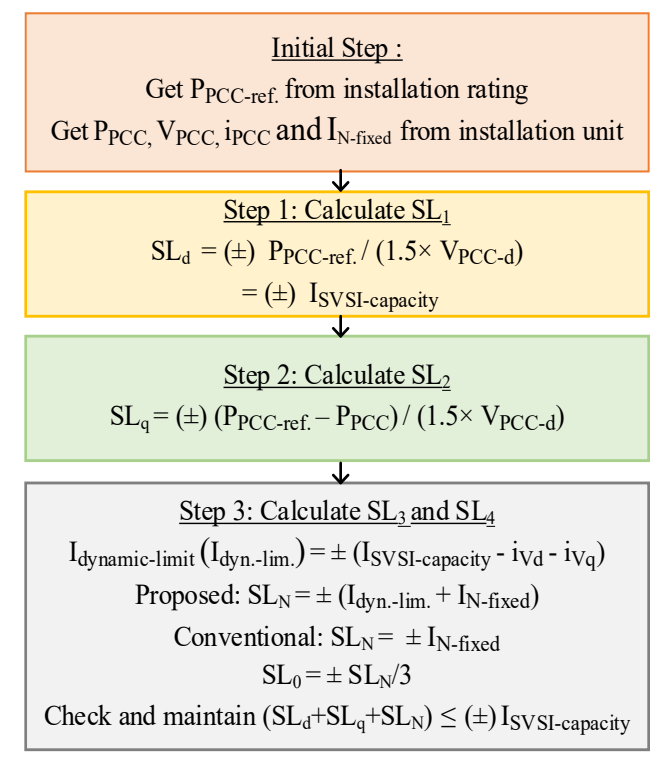

Figure 3. Proposed SVSI capacity-distribution method.

Conventionally, the neutral-current controller only uses fixed capacity operation [10], [16], however, in this paper, a novel capacity allocation method is presented for CC (iii) and (iv) in step 3 . Any remaining capacity after the CC (i) and (ii) operations will be added to the fixed capacity limit, and the $\mathrm{SL}_{\mathrm{N}}$ and $\mathrm{SL}_{0}$ limits will be changed dynamically to provide enhancement to the neutral-current compensation. An additional protection with $\mathrm{SL}_{\mathrm{N}}$ is included to avoid overloading the SVSI switches in all operating conditions. Depending on the load consumption from different distribution areas, the capacity distribution can have different control effects. For example, commercial loads, such as university buildings, are generally located close to a DT and experience peak load demand during the daytime, whereas residential loads are at different distances from the DT and experience peak load demand from late afternoon to early at night. Therefore, the power generation from a PV system can be effectively used with commercial loads to reduce the peak load demand without causing any significant voltage rise at the PCC, which on the other hand is a common problem in residential areas [19]. Therefore, depending on design requirements and electricity standards, the remaining capacity after CC (i) can be entirely utilized for CC (iii) with commercial loads to provide higher unbalance compensation, as is discussed in the results and discussion section.

\section{STABILITY ANALYSIS}

The Bode plot and small-signal analysis are presented in this section to verify the stable performance from the designed controllers with network contingencies generated from different 
transmission conductors. The controller transfer functions are derived considering positive- and zero-sequence parameters of the conductors and are shown in (A-1) and (A-2) in the Appendix [10]. A small-signal model for the PV-SVSI system is also designed considering the effect of both the positive- and zerosequence parameters of the conductors to demonstrate the stable operating region with different network contingencies as [20]:

$$
X=\left[\begin{array}{lllll}
\hat{l}_{V d} & \hat{\imath}_{V q} & \hat{\imath}_{V 0} & \hat{\imath}_{P C C C-d} & \hat{\imath}_{P C C-q}
\end{array}\right.
$$

In this paper, two different conductors are utilised to demonstrate the effect of network contingencies on the system stability. The parameters of the conductors are shown in Table A-I in the Appendix. Different conductors have different values of $\mathrm{L}_{\mathrm{T}}, \mathrm{r}_{\mathrm{T}}, \mathrm{L}_{\mathrm{Tn}}$ and $\mathrm{r}_{\mathrm{Tn}}$ which cause variations in the $\mathrm{R}_{+} / \mathrm{X}_{+}$and $\mathrm{R}_{0} / \mathrm{X}_{0}$ ratios in the network. Therefore, the designed SVSI system needs to provide stable performance with the same control parameters despite changes in the network or environmental parameters. The Bode plots are shown in Fig. 4, and it can be seen that the designed controllers have sufficient gains of $12 \mathrm{~dB}$ and $24 \mathrm{~dB}$, and phase margins of 58.8 degrees (deg) and $~ 58.9$ degrees. The crossover frequencies $\left(\omega_{\mathrm{c}}\right)$ are $5.17 \times 10^{3} \mathrm{rad} / \mathrm{s}$ and $5.58 \times 10^{3} \mathrm{rad} / \mathrm{s}$ respectively. This ensures robust controller performance from the designed system irrespective of external disturbances in the LV network.
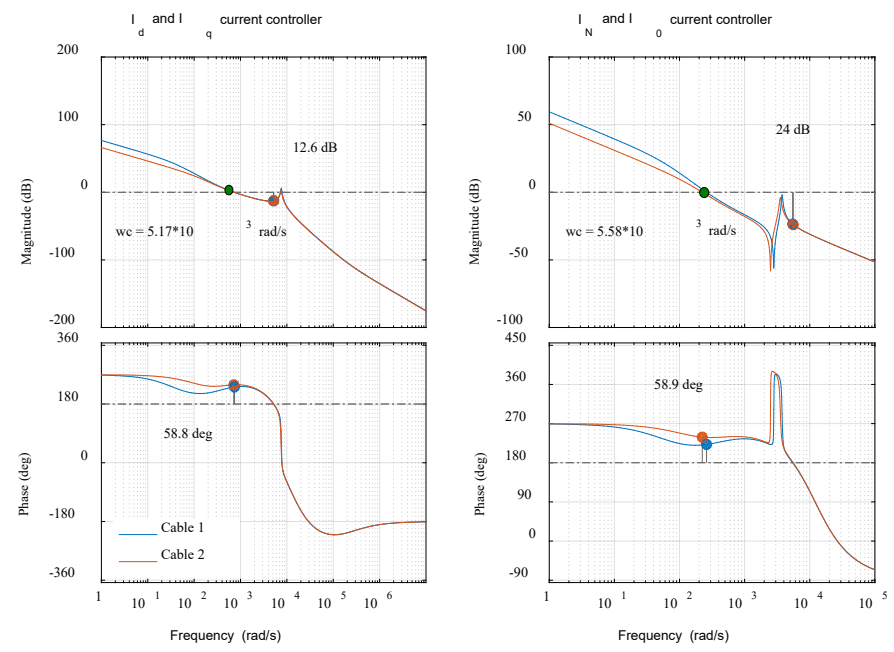

Figure 4. Bode-plot analysis of current-controllers.

To analyze the eigenvalues of the system with different conductors, a small-signal equivalent circuit model with variable transmission-line parameters as shown in Fig. 5 is used.

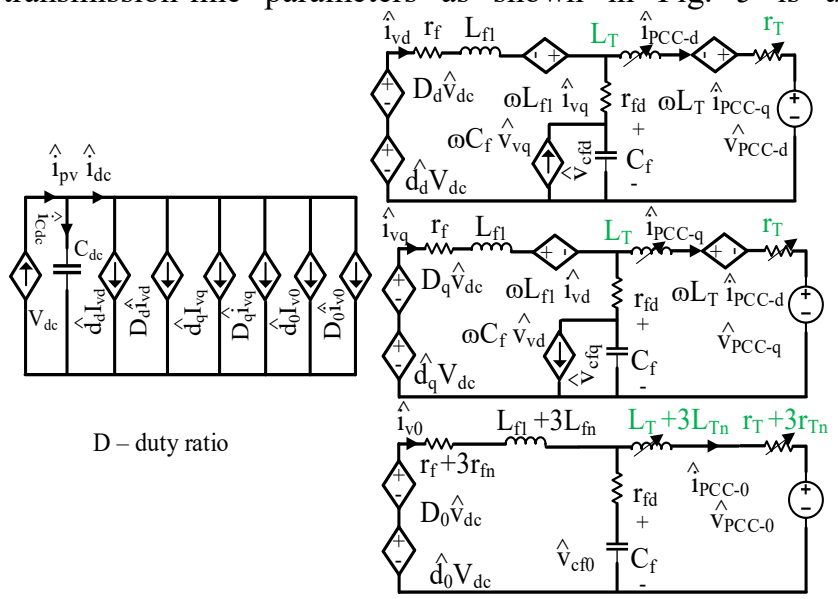

Figure 5. Small-signal equivalent-circuit model of 4L SVSI with LCL filter.

$$
\dot{X}=A X+B U ; Y=C X+D U
$$

where $Y=\left[\begin{array}{llll}\hat{l}_{P C C-d} & \hat{l}_{P C C-q} & \hat{\imath}_{v 0} & \hat{v}_{d c}\end{array}\right]^{T}$,

$U=\left[\begin{array}{llllll}\hat{d}_{d} & \hat{d}_{q} & \hat{d}_{0} & \hat{v}_{P C C-d} & \hat{v}_{P C C-q} & \hat{v}_{P C C-0}\end{array}\right]^{T}$

Matrices, A, B, C and D are given in the Appendix.

$$
\left.\hat{\imath}_{P C C-0} \quad \hat{v}_{c f d} \quad \hat{v}_{c f q} \quad \hat{v}_{c f 0} \quad \hat{v}_{d c}\right]^{T}
$$

Eigenvalue analysis provides the small-signal behavior of the system at a particular operating condition for a particular $\mathrm{R} / \mathrm{X}$ ratio and does not take into account the nonlinear behavior of controllers at large system perturbations. Therefore, both timedomain simulation and nodal analysis are used to ensure the robustness of the designed control system. It can be seen from (1)-(7) that the PV-SVSI system is designed as a tenth-order system which will have a total of ten eigenvalues [21]. For two different cables, there will be a total of twenty eigenvalues, and the results are shown in Fig. 6. It is evident from Fig. 6 that the eigenvalues shift significantly with variations in the parameters $\left(\mathrm{L}_{\mathrm{T}}, \mathrm{r}_{\mathrm{T}}, \mathrm{L}_{\mathrm{Tn}}\right.$ and $\mathrm{r}_{\mathrm{Tn}}$ ) of the two cables. Despite the eigenvalue movements, the designed current controllers operate within the stable region (left-hand plane of the 0-real axis). From the Bodeplot and small-signal analysis, it is evident that the designed current controllers can maintain stable performance under different network conditions and divergent variations in solar irradiance and loads, as presented in the next section.

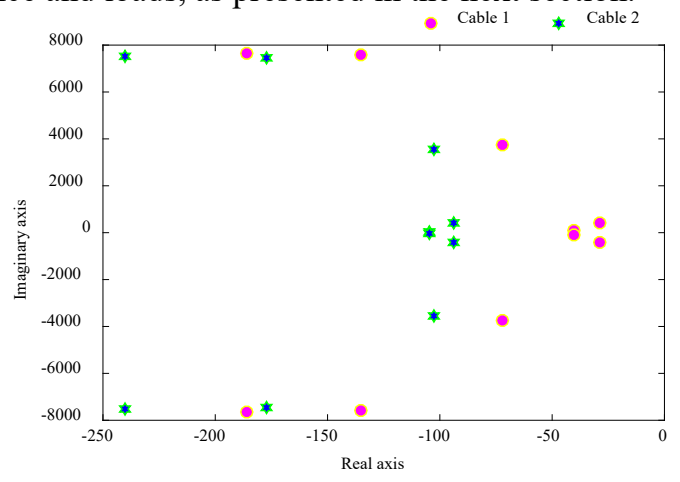

Figure 6. Small-signal analysis of the designed SVSI.

\section{RESULTS AND DISCUSSION}

The performance of the designed system with the proposed SVSI capacity control method is demonstrated using results from different case studies performed in PSCAD/EMTDC software and an experimental prototype using a real-time DSP microcontroller. Details are discussed in the next subsections.

\section{A. Simulation results from PSCAD/EMTDC:}

A real 44-bus 3P-4W LV distribution network as shown in Fig. 7 is used as a test system to verify the performance of the designed SVSI with commercial loads [10]. The DT is supplied from the $33 / 11 \mathrm{kV}$ upstream network (1.5 km long) and the secondary side of the DT $(11 / 0.420 \mathrm{kV})$ is reconstructed with a $\pi$ transmission-line model to connect the commercial load. The distance between the load and the DT is chosen as $100 \mathrm{~m}$. 


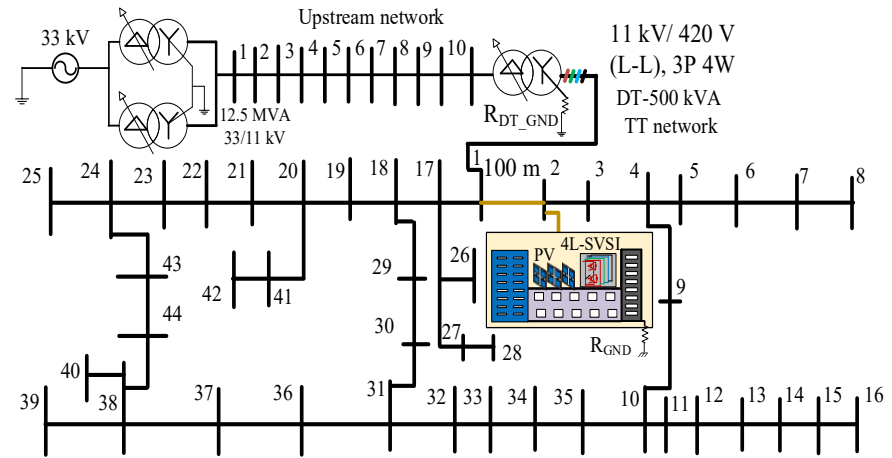

Figure 7. Commercial load connection with LV network

The commercial load data is collected using smart meters installed in the university building, and retrieved using PI datalink software with a 1-minute resolution for two consecutive days, Sunday $4^{\text {th }}$ (weekend) and Monday $5^{\text {th }}$ (weekday) September 2016. The variation of peak load demands is shown in Fig. 8. The university building has various motors and nonlinear loads which result in a significant phase unbalance and neutral current. The solar irradiance data is collected using a pyranometer with 1-minute resolution of data. The solar irradiance data and the effect of different PV installations on peak load demand are shown in Fig. 9.
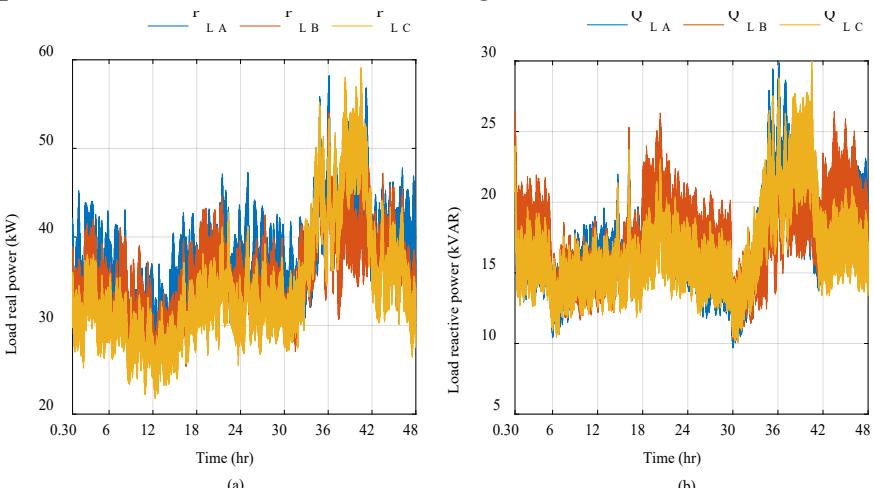

Figure 8. Commercial load profiles: (a) active, and (b) reactive power. ${ }^{\mathrm{P}}{ }_{\mathrm{PV}}{ }^{(15 \mathrm{~kW})}-{ }_{\mathrm{PV}}^{\mathrm{P}}{ }^{(28 \mathrm{~kW})}-{ }_{\mathrm{grid}}^{\mathrm{P}}{ }^{(\text {load })}-{ }_{\mathrm{grid}}{ }^{\mathrm{P}}{ }^{(15 \mathrm{~kW})}-{ }_{\mathrm{grid}}{ }^{\mathrm{P}}{ }^{(28 \mathrm{~kW})}$

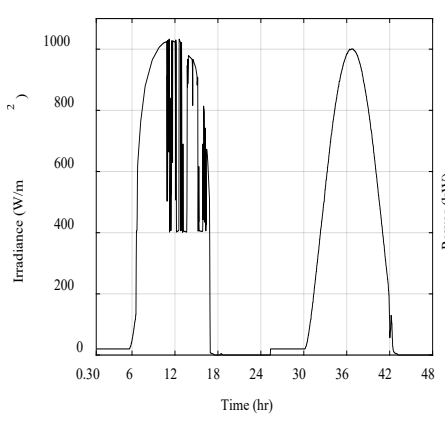

(a)

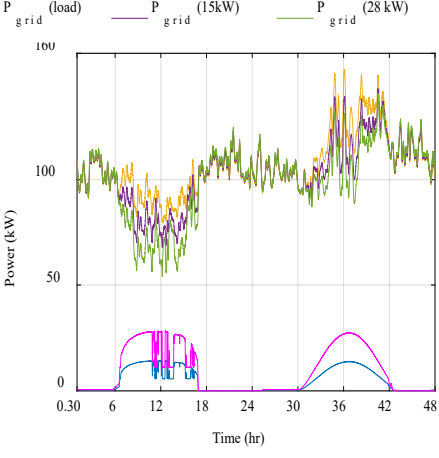

Figure 9. (a) Solar irradiance and (b) PV and grid active power.

It can be seen from Fig. 9 that an increase in PV installation capacity can reduce the peak load demand significantly. In this paper, the $3 \mathrm{P}-4 \mathrm{~L}$ VSI is designed as a $15 \mathrm{kVA}$ unit with a maximum $14.5 \mathrm{~kW}$ power export from the PV system at the standard testing condition. With the LV grid supply of $240 \mathrm{~V}_{\mathrm{L}-\mathrm{N}}$, the maximum current capacity of the SVSI is calculated as \pm 29 A which is automatically selected in $\mathrm{SL}_{d}$ for $\mathrm{CC}$ (i), i.e. activepower regulation. The external dc-bus voltage controller regulates the dc bus at $700 \mathrm{~V}$. Any remaining current capacity from the rated total capacity, i.e. $\pm 29 \mathrm{~A}$, is used for $\mathrm{SL}_{\mathrm{q}}$ and $\mathrm{SL}_{\mathrm{N}}$.
As the total capacity of the SVSI is fixed for a particular installation, an additional protection limiter is designed to keep the combined capacity requirement from CC (i)-(iv) within the SVSI rated limit, i.e. $\pm 29 \mathrm{~A}$, as shown in step 3 in Fig. 3. The details about the parameters used in the simulation model are presented in the Appendix.

The PCC voltage profile and load-generated neutral current are shown in Figs. 10 (a) and (b) respectively.
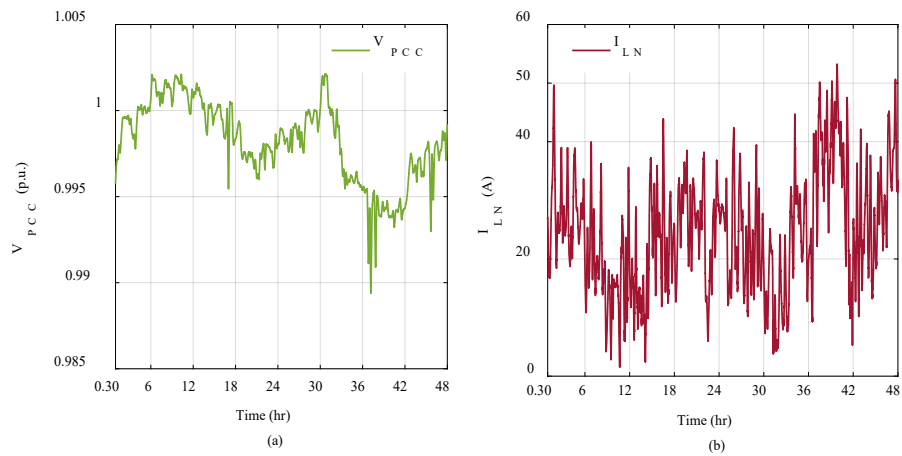

Figure 10. (a) Voltage, and (b) load generated neutral current at PCC.

It can be seen from Fig. 10 (a) that the PCC voltage remains quite close to 1 p.u. despite high load demand during the daytime. This is due to the shorter distance from the DT to the commercial load. Any changes in the voltage due to active-power export (swell) or high load demand (sag) can be regulated close to 1 p.u. by the DT. Therefore, for commercial loads, the PCC voltage regulation from the PV-SVSI system becomes optional, unlike the requirements for residential loads [10], [22]. From Fig. 10 (b), it is evident that the considered commercial load can generate a maximum of $50 \mathrm{~A}(\mathrm{rms})$ neutral current at the PCC during weekdays, which can cause overloading of the neutral conductor and can also increase the neutral to ground potential. Therefore, the 3P-4L SVSI is designed to utilize lower capacity from the SVSI for CC (ii) operation and higher capacity for unbalance compensation at the PCC, i.e. CC (iii) and (iv).

The SVSI capacity distributions for CC (iii) based on different case conditions are presented in Table I and Fig. 11 below. Table I shows the SVSI capacity for CC (iii) operation only. The case (a) represents the load-only condition without any SVSI connection in the system.

TABLE I: Different case condition descriptions with $\mathrm{S}_{\mathrm{LN}}$ maximum capacity

\begin{tabular}{|l|l|c|c|}
\hline Case & $\begin{array}{l}\text { Fixed } \\
\text { capacity }\end{array}$ & $\begin{array}{c}\text { Dynamic capacity } \\
\text { (proposed) }\end{array}$ & $\begin{array}{c}\mathrm{S}_{\text {LN-Max. }} \\
\text { (A) }\end{array}$ \\
\hline (b) & No & Remaining capacity after CC (i) and (ii) & \pm 14 \\
\hline (c) & No & Remaining capacity after CC (i) & \pm 28 \\
\hline (d) & $10 \mathrm{~A}$ & No & \pm 10 \\
\hline d $\left.^{*}\right)$ & $10 \mathrm{~A}$ & Remaining capacity after CC (i) and (ii) & \pm 24 \\
\hline$(\mathrm{e})$ & $20 \mathrm{~A}$ & No & \pm 20 \\
\hline $\left.\mathrm{e}^{*}\right)$ & $20 \mathrm{~A}$ & Remaining capacity after CC (i) and (ii) & \pm 29 \\
\hline
\end{tabular}




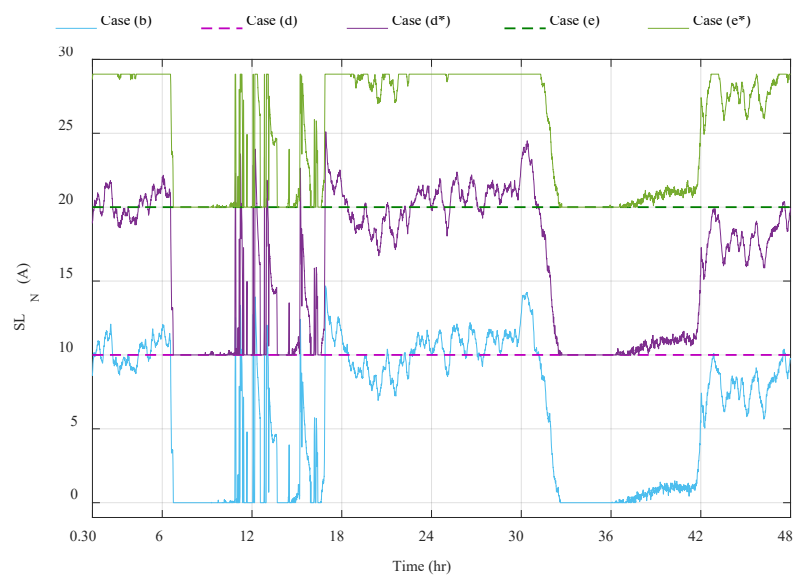

Figure 11. SVSI capacity availability comparison.

It can be seen from Fig. 11 that, utilising the proposed capacity enhancement method, even with the same SVSI total capacity, higher neutral-current compensation is possible with cases (c), $\left(d^{*}\right)$ and $\left(e^{*}\right)$. The SVSI system with the proposed method in case $\left(d^{*}\right)$ with lower $\mathrm{I}_{\mathrm{N}-\text { fix. }}$ can perform similar compensation in many instances to conventional fixed-capacity operation in case (e) with higher $\mathrm{I}_{\mathrm{N} \text {-fix. }}$. Case $\left(\mathrm{e}^{*}\right)$ has a higher fixed limit of $\pm 20 \mathrm{~A}$ and dynamic limit of max $\pm 14 \mathrm{~A}$, however, the control method ensures that the $S_{\mathrm{LN}}$ maximum remains less than the SVSI total limit, i.e. \pm 29 A. This proves that higher-capacity neutral compensation is possible without increasing the rating of the SVSI unit.

Fig. 12 shows the performance comparison between a fixed and a dynamic capacity 3P-4L SVSI for neutral-current compensation at the PCC with different SVSI capacity limits. The performance comparison among different case conditions is compared based on the amount of compensated neutral current ( Load-N $_{\text {- I }}$ SvSI-N) at the PCC, for a weekend in Fig. 12 (a) and for a weekday in Fig. 12 (b) respectively. The main focus is given to the performance for cases ' $d$ ', ' $\mathrm{d}^{*}$ ', ' $\mathrm{e}$ ' and ' $\mathrm{e}$ '. As the loads from the university building have different load demands for weekend and weekday, the performance comparison is presented separately in Fig. 12. It is obvious from Fig. 12 that, during peak PV generation periods, there are insignificant differences in fixed and dynamic capacity SVSI performance. However, apart from peak PV generation periods, the cases $\left(\mathrm{d}^{*}\right)$ and $\left(\mathrm{e}^{*}\right)$ with the proposed method can outperform the fixed-capacity SVSI in cases (d) and (e) respectively. In addition, the proposed method in case $\left(d^{*}\right)$ with a lower SVSI capacity rating can achieve similar unbalance compensation performance to case (e) with a higher SVSI fixed capacity rating in many instances for both days outside the peak PV generation period. This demonstrates that the SVSI with the proposed method can provide better unbalance compensation without any additional resources or requirement of higher SVSI nameplate rating.
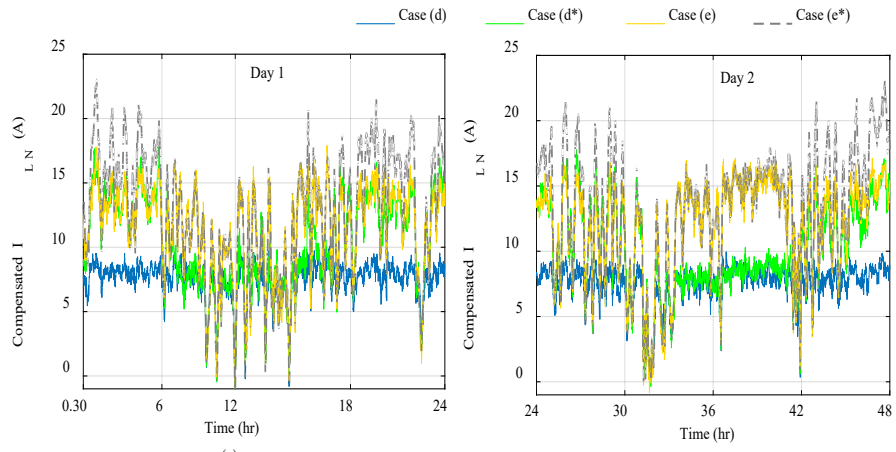

Figure 12. Amount of neutral current compensated at PCC with different cases.

The phase currents and $\mathrm{CC}$ (iii), i.e. the neutral-current controller, operations for cases (d), $\left(\mathrm{d}^{*}\right),(\mathrm{e})$ and $\left(\mathrm{e}^{*}\right)$ are shown in Figs. 13 (a) - (h). The improvement in the phase-balancing operation is presented with the improvement in the current unbalance factor (CUF) [10], and the corresponding results are shown in Fig. 13.
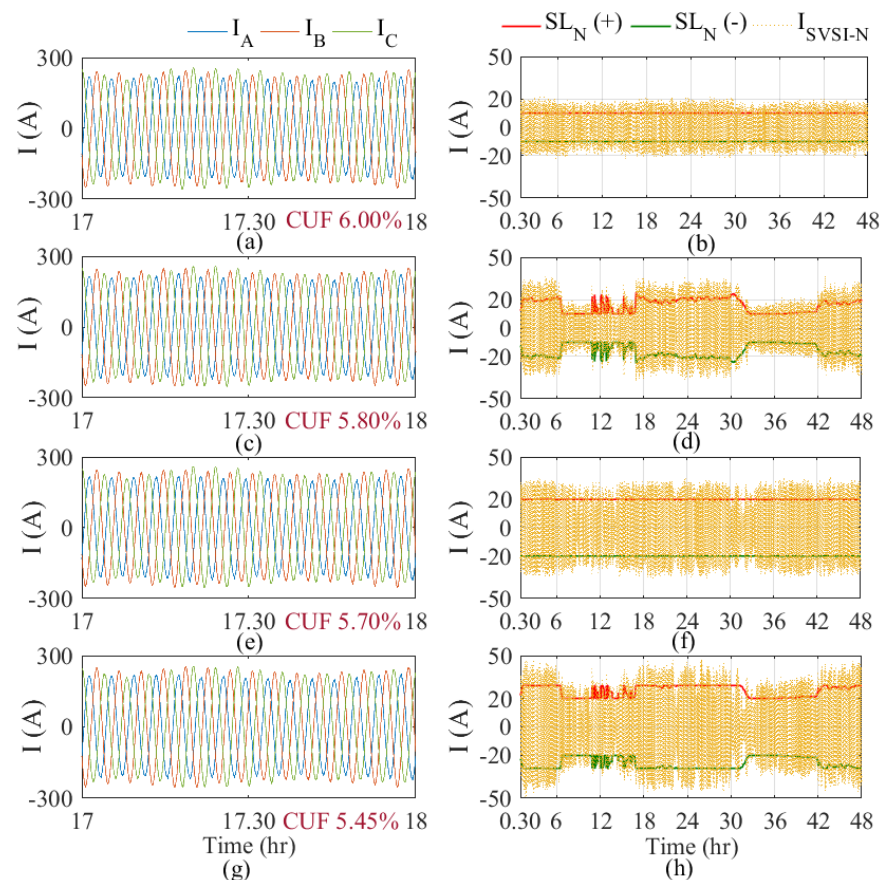

Figure 13. Phase and neutral currents of case (d) in (a) and (b), case (d*) in (c) and (d), case (e) in (e) and (f), and case ( $\left.\mathrm{e}^{*}\right)$ in (g) and (h) respectively.

It is evident from Fig. 13 that the proposed method in cases $\left(\mathrm{d}^{*}\right)$ and $\left(\mathrm{e}^{*}\right)$ can improve the CUF by around $0.20 \%$ and $0.25 \%$ over cases (d) and (e) respectively. The neutral current compensation with the fixed and proposed method can easily be understood from Figs. 13 (b), (d), (f) and (h). It can also be seen that the controller can robustly follow the neutral-current reference to achieve faster response and better power quality. The performance improvement using the proposed method is further verified using the experimental results in the next section.

\section{B. Experimental results:}

The performance of the designed 3P-4L SVSI is demonstrated on a laboratory scale, as shown in Fig. 14 (a). The control system and capacity-distribution method shown in Figs. 2 and 3 are implemented in Code Composer Studio (CCS) to control the real-time TMS320F28335 DSP microcontroller to generate the sinusoidal pulse width modulation signals (SPWM). In the experiment, a constant dc power supply is used to replace the PV 
source. The Semikron Semiteach 3P-3L system is modified to operate as a 3P-4L SVSI by replacing the chopper module (SKM50GAL12T4) with a half-bridge switching module (SKM50GB123D) [23]. Three single-phase programmable loads by Chroma are used to generate unbalance at the PCC. A 3P stepdown variable transformer with a $10 \mathrm{~A} /$ phase rating is used to provide a $3 \mathrm{P}-4 \mathrm{~W}$ supply to the system from the main grid. To maintain laboratory safety measures, experimental studies are performed with grid supply of $50 \mathrm{~V}_{\text {rms }}$. The switchgear controller unit hosts the real-time microcontroller and generates switching signals for the 3P-4L Semiteach unit [24]. Hall-effect transducers, four voltage (LV 25-P) and six current sensors (LA $100-\mathrm{P})$, are used to feed back the real-time sinusoidal voltage and current data from the PCC to the switchgear controller unit where the abc-dq0 transformation is carried out. A Metrel energy master power quality analyser is used along with Hioki current clamps to measure the power quality of the system. A switching frequency of $9 \mathrm{kHz}$ is used for the SPWM and the switching signals are transmitted using BNC modules integrated with the switchgear controller. The switchgear module with real time DSP microcontroller is connected to the host computer via a JTAG cable and controlled in real-time from the CCS. The detailed connection diagram of the experimental system is shown in Fig. 14 (b). The controller is configured with double rate PWMs with a control rate of $13 \mathrm{kHz}$ (time step $38 \mu \mathrm{s}$ ) and $3 \mu \mathrm{s}$ dead time. A four-channel oscilloscope from Tektronix is used to obtain the SVSI outputs from the controller unit. Details of the experimental components are shown in Table A-II in the Appendix. The experimental results are presented focusing on:

(i) current-control operations with saturation limiters (SL), and

(ii) performance comparison of the proposed and conventional unbalance compensation using the 3P-4L SVSI.

\section{B.1 Operation with saturation limiters (SL):}

To demonstrate the operation of the proposed unbalancecompensation method with the dynamic saturation limiters, the 3P-4L SVSI is set to control $\mathrm{V}_{\text {PCC-q }}$ as $0 \mathrm{~V}$ and $\mathrm{V}_{\text {PCC-d }}$ as $70.7 \mathrm{~V}$ $\left(\sqrt{2} V_{\text {grid }}\right)$ using the phase-locked loop (PLL). The dc voltage regulator is set to regulate the dc bus voltage at a constant $140 \mathrm{~V}$. The simulation model is scaled down to demonstrate the performance comparison of the proposed unbalance compensation method with experimental reults.

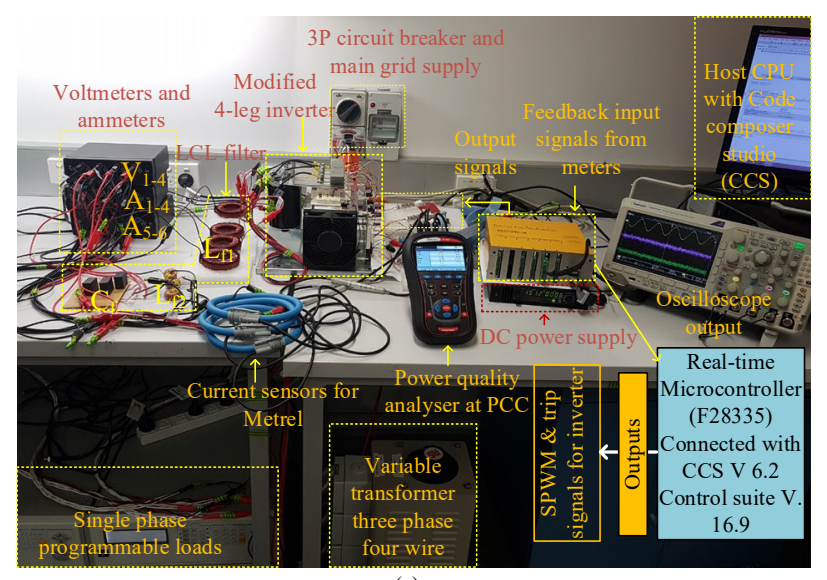

(a)

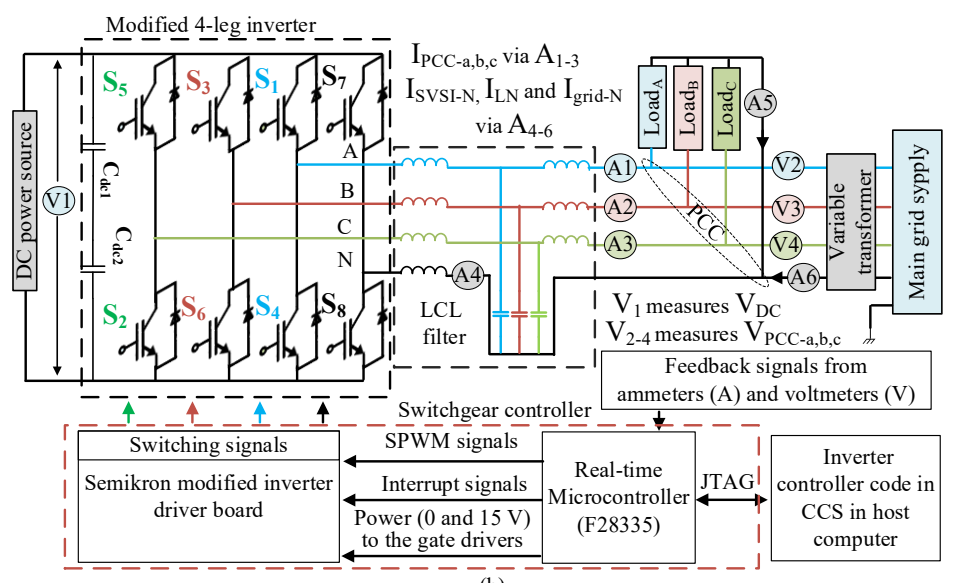

(b)

Figure 14. (a) Actual setup and (b) simplified block diagram of the 3P-4L SVSI experimental setup.
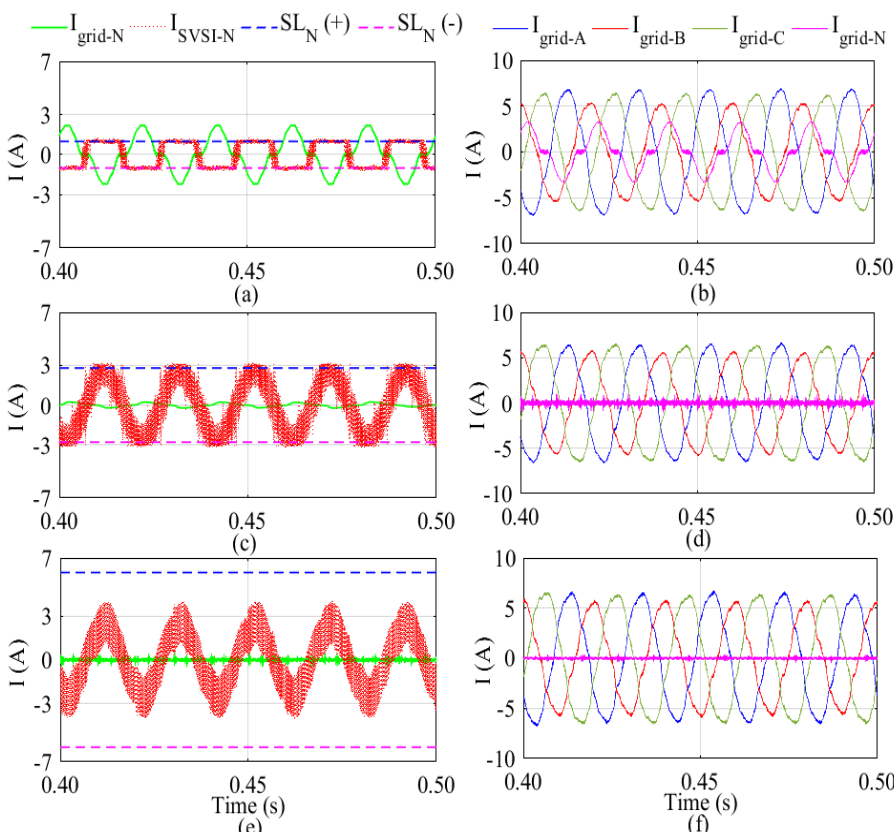

0.50
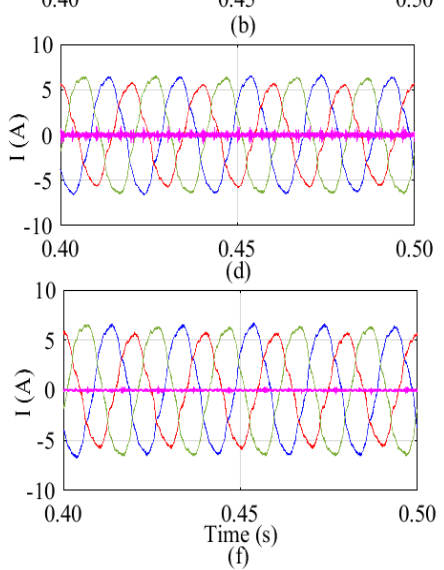

Figure 15. Simulation outputs of $\mathrm{CC}$ (iii) and grid currents with $\mathrm{SL}_{\mathrm{N}}( \pm 1 \mathrm{~A})$ in (a) and (b), $\mathrm{SL}_{\mathrm{N}}( \pm 3 \mathrm{~A})$ in (c) and (d), and $\mathrm{SL}_{\mathrm{N}}( \pm 6 \mathrm{~A})$ in (e) and (f).

The total capacity of the SVSI is set to $\pm 6 \mathrm{~A}$. The loads are set as constant-power loads to consume $5 \mathrm{~A}, 3 \mathrm{~A}$ and $4 \mathrm{~A}$ currents in three phases which result in around $3 \mathrm{~A}$ of neutral current. The $\mathrm{SL}_{\mathrm{N}}$ limit is manually changed to $( \pm) 1 \mathrm{~A}, 3 \mathrm{~A}$ and $6 \mathrm{~A}$, and the corresponding effects on the phase currents are shown from the simulation model in Fig. 15 and from the experimental set up in Fig. 16 respectively. Comparisons between the simulation and experimental results are summarised in Table II.

TABLE II: Results summary from Figs. 15 and 16

\begin{tabular}{|c|c|c|c|c|c|c|}
\hline \multicolumn{6}{|c|}{ Constant Power load, $\mathrm{I}_{\mathrm{LA}}=5 \mathrm{~A}, \mathrm{I}_{\mathrm{LB}}=3 \mathrm{~A}, \mathrm{I}_{\mathrm{LC}}=4 \mathrm{~A}$, and $\mathrm{I}_{\mathrm{LN}}=3 \mathrm{~A}$} \\
\hline Parameters & \multicolumn{3}{|c|}{ Simulation } & \multicolumn{3}{c|}{ Experimental } \\
\hline $\mathrm{SL}_{\mathrm{N}}(\mathrm{A})$ & \pm 1 & \pm 3 & \pm 6 & \pm 1 & \pm 3 & \pm 6 \\
\hline $\mathrm{I}_{\text {grid-N }}\left(\mathrm{A}_{\mathrm{rms}}\right)$ & 2 & 0.5 & $\sim 0$ & 2.3 & 0.9 & $\sim 0$ \\
\hline $\mathrm{CUF}(\%)$ & 11 & 8.3 & 6.5 & 11.5 & 9.1 & 7.2 \\
\hline $\mathrm{I}_{\mathrm{THD}}(\%)$ & 4.3 & 4 & 3.8 & 4.7 & 4.3 & 4 \\
\hline
\end{tabular}

It is evident from both simulation and experimental results that increasing the $\mathrm{SL}_{\mathrm{N}}$ limit can result in an increase in neutral current compensation and can improve the phase balancing at the PCC. The simulation results indicate better performance than the 


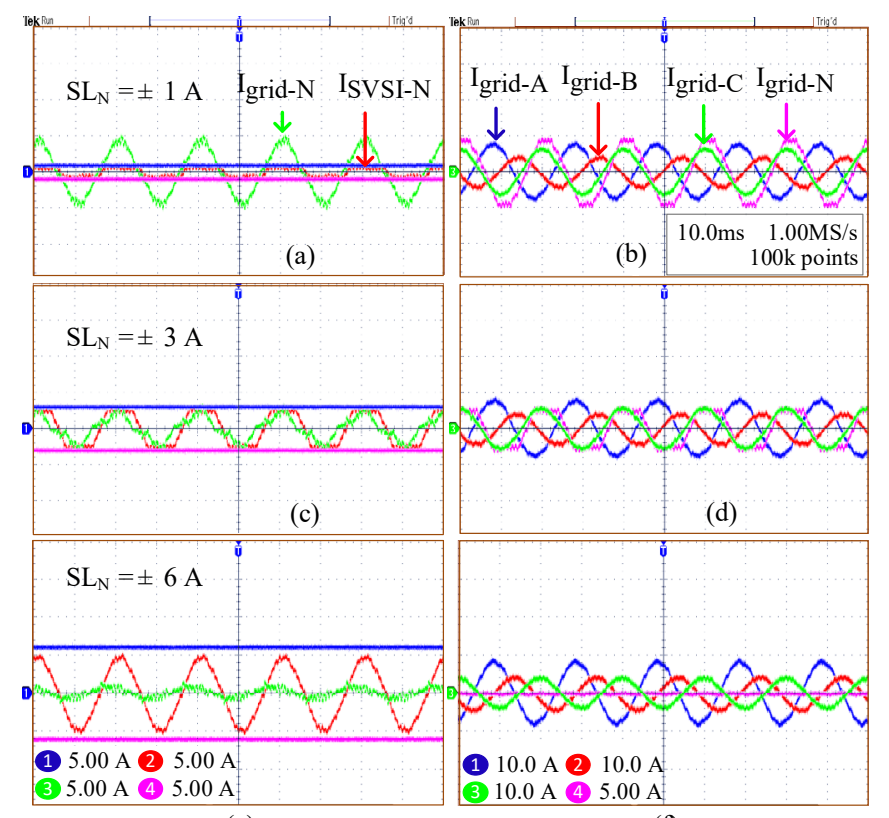

(e)

Figure 16. Experimental outputs of CC (iii) and grid currents with $\mathrm{SL}_{\mathrm{N}}( \pm 1 \mathrm{~A})$ in (a) and (b), $\mathrm{SL}_{\mathrm{N}}( \pm 3 \mathrm{~A})$ in (c) and (d), and $\mathrm{SL}_{\mathrm{N}}( \pm 6 \mathrm{~A})$ in (e) and (f).

experimental results due to the ideal conditions in the simulation network, however results from both platforms verify the concept of saturation limit utilization with CC (iii). This also demonstrates that the designed PI controller with the proposed capacity utilization method can perform robustly without any significant delay or overshoot in the output currents.

Instead of allocating fixed $\mathrm{SL}_{\mathrm{N}}$ capacity, the proposed methodology utilizes dynamically varying capacity to achieve better unbalance-compensation using the 3P-4L SVSI. The performance of the designed controllers with the proposed unbalance-compensation method is demonstrated in both simulation and experimental platforms in Figs. 17 and 18 respectively. The loads are configured to generate $3 \mathrm{~A}$ of neutral current at the PCC as shown in Figs. 17 (a) and 18 (a). The neutral-current compensation using the full SVSI capacity ( \pm $6 \mathrm{~A}$ ), i.e. with $\mathrm{I}_{\mathrm{d}-\text {-ref. }}$ and $\mathrm{I}_{\mathrm{q}-\text {-ref. }}$ set to $0 \mathrm{~A}$, is shown in Figs. 17 (b) and 18 (b). It is mentioned in Section II that a fixed neutralcompensation capacity, $\mathrm{I}_{\mathrm{N} \text {-fix. }}(2 \mathrm{~A})$, is allocated for the fourth-leg operation to provide uninterruptible unbalance compensation. Any remaining capacity after CC (i) and (ii) operation will add
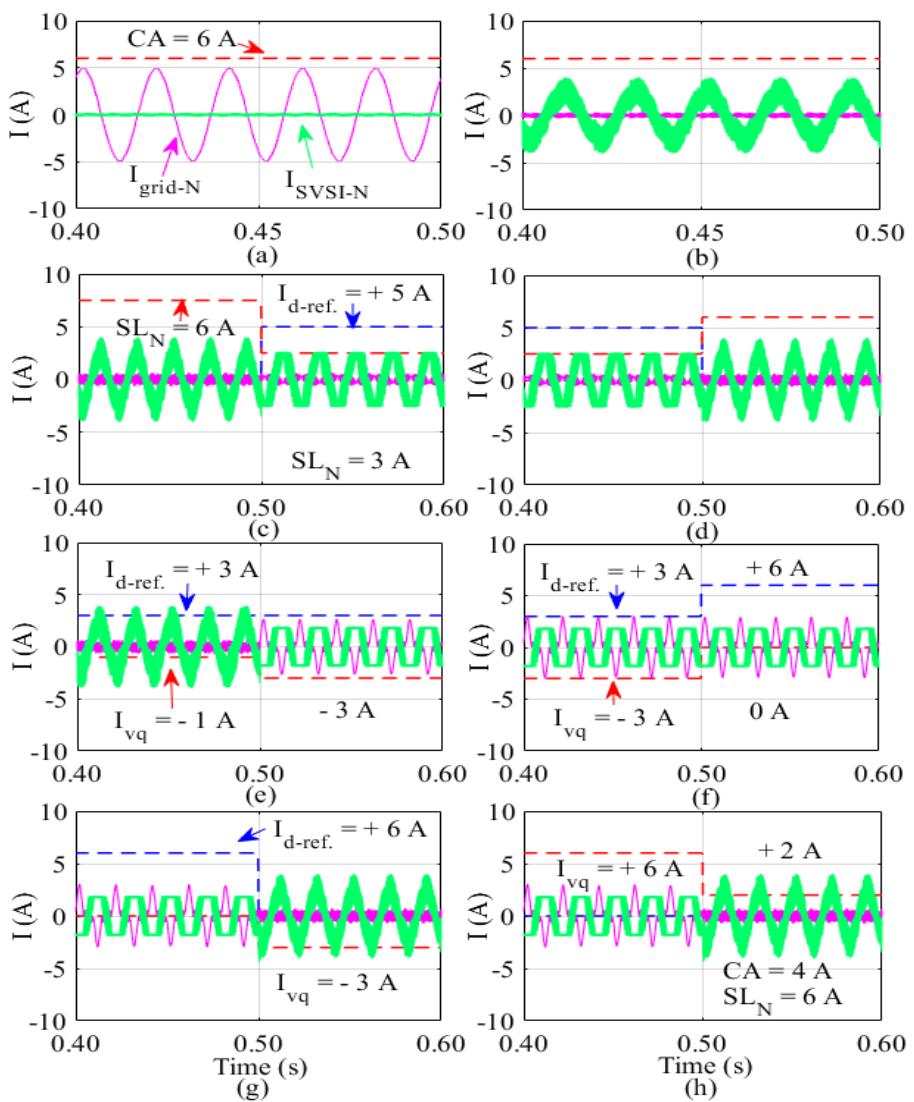

Figure 17. Simulation outputs of PCC neutral current (a) without, and (b) with full capacity compensation; proposed capacity enhancement by changing $\mathrm{I}_{\mathrm{d} \text {-ref. }}$ from (c) 0 to $5 \mathrm{~A}$, and (d) 5 to $0 \mathrm{~A}$; by changing $\mathrm{I}_{\mathrm{q}-\text { ref. }}$ from (e) -1 to $-3 \mathrm{~A}$, and (f) -3 to $0 \mathrm{~A}$; by changing $(\mathrm{g}) \mathrm{I}_{\mathrm{d}-\text { ref. }}$ from 6 to $0 \mathrm{~A}$, and $(\mathrm{h}) \mathrm{I}_{\mathrm{q} \text {-ref. from }} 6$ to $2 \mathrm{~A}$.

to $\mathrm{I}_{\mathrm{N} \text {-fix., }}$ and the controller will ensure that it does not exceed the total SVSI capacity, i.e. $\pm 6 \mathrm{~A}$ in this case. Without the additional protection in the saturation limiter, the $\mathrm{SL}_{\mathrm{N}}$ would have $\pm 8 \mathrm{~A}$ instead of the $\pm 6 \mathrm{~A}$ limit, resulting in an overloading condition and damage to the SVSI switches. The SVSI capacity distribution is further demonstrated by changing $\mathrm{I}_{\mathrm{d}-\text { ref. }}$ from 0 to 5 A in Figs. 17 (c) and 18 (c), and from 5 to 0 A in Figs. 17 (d) and $18(\mathrm{~d}) . \mathrm{I}_{\mathrm{d} \text {-ref. }}$ is changed from +5 to $0 \mathrm{~A}$, changing the capacity available (CA) from 1 to $6 \mathrm{~A}$, which adds up to $\mathrm{I}_{\mathrm{N} \text {-fix. }}$. resulting in $\mathrm{SL}_{\mathrm{N}}$ limits from \pm 3 to $\pm 6 \mathrm{~A}$ as shown in Figs. 18 (c) and (d) respectively. CC (ii) is designed to operate utilizing any available capacity after the active-power operation, and this is illustrated from the simulation model in Figs. 17 (e) and (f), and from the experimental setup in Figs. 18 (e) and (f) respectively. $\mathrm{I}_{\mathrm{d}-\text { ref. }}$ is kept constant at $3 \mathrm{~A}$ and $\mathrm{I}_{\mathrm{q}-\text {-ref. }}$ is changed from -1 to -3 $\mathrm{A}$, resulting in a decrease in CA from 2 to $0 \mathrm{~A}$ and in $\mathrm{SL}_{\mathrm{N}}$ from 4 to $2 \mathrm{~A}$. However when $\mathrm{I}_{\mathrm{d}-\mathrm{ref}}$ is changed to operate with full VSI capacity, the $\mathrm{I}_{\mathrm{q}}$ current becomes $0 \mathrm{~A}$ due to the lack of available capacity, as shown in Figs. 17 (f) and 18 (f). Similarly when $I_{d-}$ ref. is changed from full capacity to zero with $\mathrm{I}_{\mathrm{q}-\text { ref. }}$ set as $-3 \mathrm{~A}$, it resumes CC (ii) operation without any delay or stability issues as can be seen from Figs. $17(\mathrm{~g})$ and $18(\mathrm{~g})$. This also creates some available capacity (3 A) in the SVSI, which is utilized with CC (iii) to provide better neutral-current compensation as can be seen in Figs. 17 (g) and 18 (g). In Figs. 17 (h) and 18 (h), instead of a manual reference changing operation, the dc voltage regulator is used to generate $\mathrm{I}_{\mathrm{d} \text {-ref., }}$ and $\mathrm{I}_{\mathrm{q}-\text {-ref. }}$ is manually controlled to supply reactive current to the grid. These results can be related to SVSI operation during the night-time when the SVSI full capacity can be utilized for either CC (ii) or 


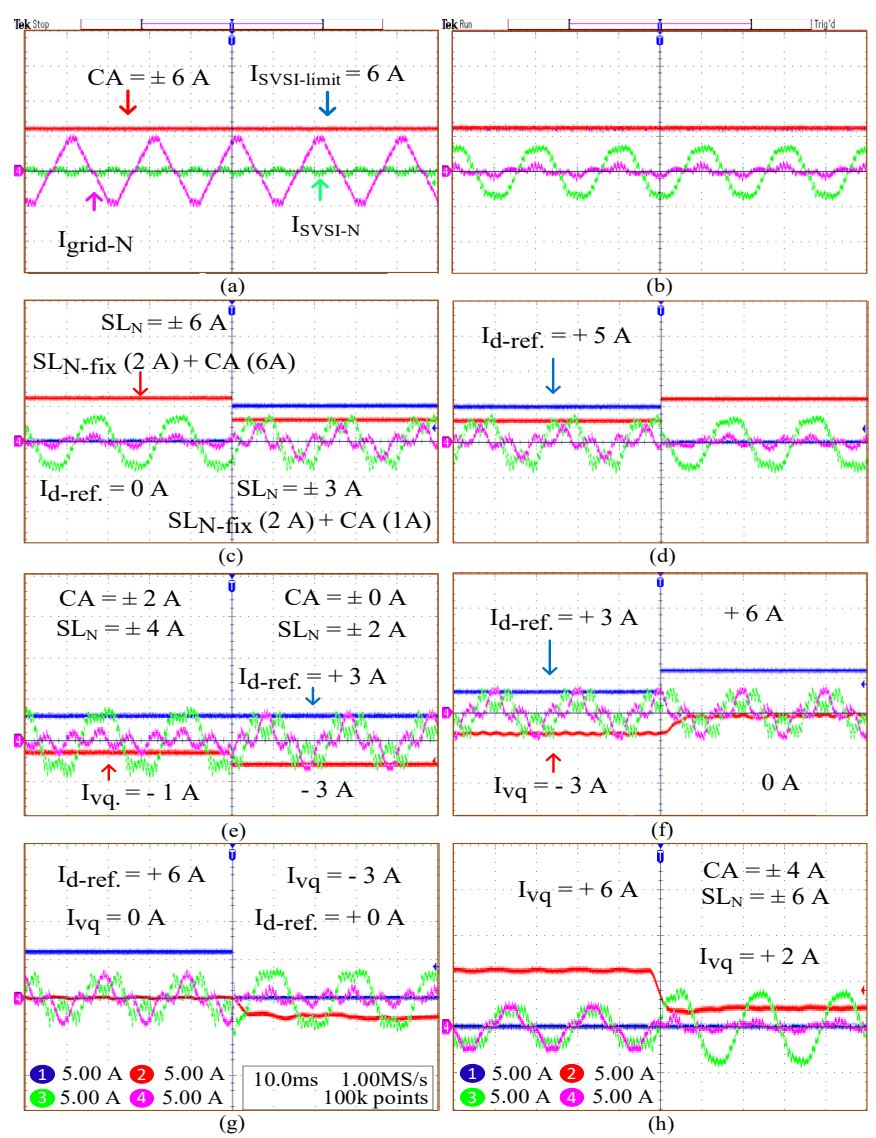

Figure 18. Experimental outputs of PCC neutral current (a) without, and (b) with full capacity compensation; proposed capacity enhancement by changing $\mathrm{I}_{\mathrm{d} \text {-ref. }}$ from (c) 0 to $5 \mathrm{~A}$, and (d) 5 to $0 \mathrm{~A}$; by changing $\mathrm{I}_{\mathrm{q}-\mathrm{ref} .}$ from (e) -1 to $-3 \mathrm{~A}$, and (f) -3 to $0 \mathrm{~A}$; by changing $(\mathrm{g}) \mathrm{I}_{\mathrm{d}-\text { ref }}$ from 6 to $0 \mathrm{~A}$, and $(\mathrm{h}) \mathrm{I}_{\mathrm{q}-\text { ref }}$ from 6 to $2 \mathrm{~A}$.

$\mathrm{CC}$ (iii) operation. Sharing the available capacity can improve the CC (iii) performance as is evident from Figs. 17 and 18.

Both simulation and experimental results prove that the proposed unbalance-current-compensation method can distribute SVSI capacity instantly to achieve higher neutral current compensation utilizing the dynamically varying saturation limiters with the designed current controllers.

\section{B.II Performance comparison with existing method:}

This case study presents an experimental performance comparison between the existing fixed-capacity and the proposed dynamic-capacity unbalance-current-compensation method using a 3P-4L SVSI, and the results are shown in Fig. 19. Vector plots, total harmonic distortion (THD) and unbalance factors are collected using a power-quality analyser meter and are used for this case study. The loads are set as constant-power loads to consume $5 \mathrm{~A}, 3 \mathrm{~A}$ and $1 \mathrm{~A}$ in three phases which generate around 3.5 A of neutral current, as shown in Fig. 19 (a). External dc $\left(\mathrm{V}_{\text {dc-ref. }} 140 \mathrm{~V}\right)$ and ac $\left(\mathrm{V}_{\text {d-ref. }} 70.7 \mathrm{~V}\right)$ voltage control loops are used, and the load-generated neutral current, i.e. $3.5 \mathrm{~A}_{\mathrm{rms}}$, is used as a reference. It can be seen from Figs. 19 (a), (c) and (e) that, even with a fixed capacity limit, the 3P-4L SVSI can significantly improve the phase balancing at the PCC with CC (iii). The phase balancing is better represented by the vector plots from Figs. 19 (b), (d) and (f). The ac voltage regulator supplies reactive current to the grid to improve the voltage sag caused by the addition of loads. With the fixed-capacity neutral-current compensation, the grid-side neutral current reduces from 3.5 to 1.5 A with the limit of a fixed 2 A capacity. The SVSI available capacity is added to the fixed $2 \mathrm{~A}$ limit and the results are shown in Fig. 19 (e). It is evident from Figs. 19 (c) and (e) that the proposed capacity allocation method provides better neutralcurrent compensation and phase balancing than the existing fixed- capacity one.
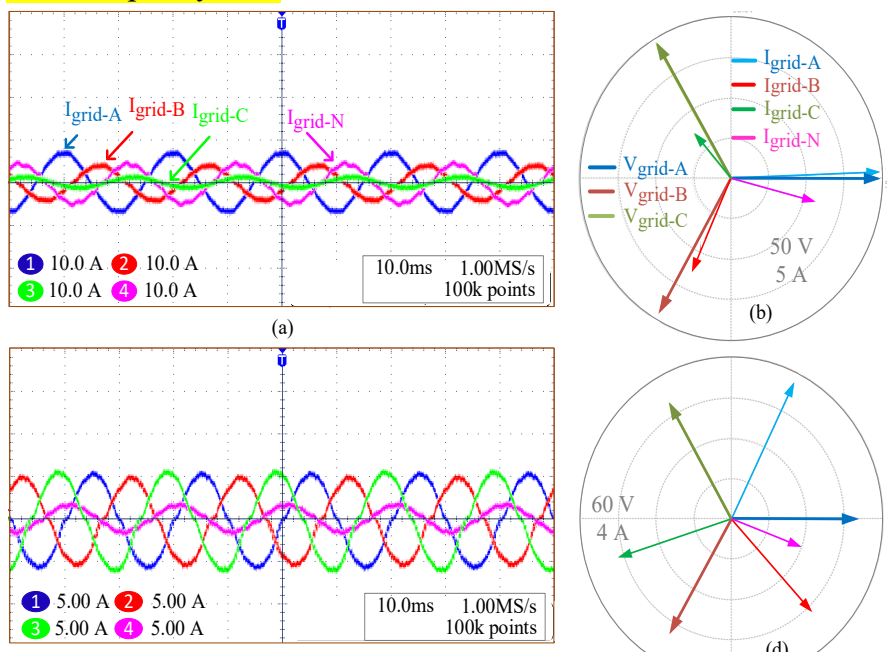

(c)
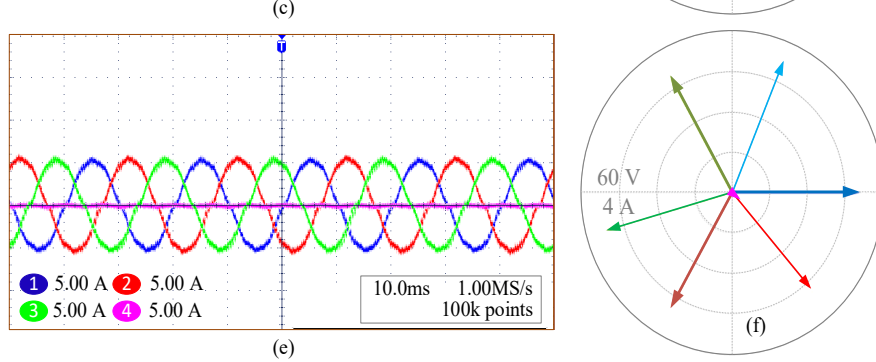

Figure 19. PCC currents and vector plots with loads in (a) and (b); SVSI with fixed capacity in (c) and (d); and SVSI with proposed method in (e) and (f).

TABLE III: Performance comparison of the SVSI from Fig. 19

\begin{tabular}{|c|c|c|c|}
\hline & \multicolumn{3}{|c|}{ Constant Power load, $\mathrm{I}_{\mathrm{LA}}=5 \mathrm{~A}, \mathrm{I}_{\mathrm{LB}}=3 \mathrm{~A}$, and $\mathrm{I}_{\mathrm{LC}}=1 \mathrm{~A}$} \\
\hline Parameter & $\begin{array}{c}\text { Load } \\
\text { only }\end{array}$ & $\begin{array}{c}\text { Fixed capacity } \\
\text { (conventional) }\end{array}$ & $\begin{array}{c}\text { Dynamic capacity } \\
\text { (proposed) }\end{array}$ \\
\hline $\mathrm{I}_{\text {grid-N }}\left(\mathrm{A}_{\text {rms }}\right.$ ) & 3.5 & 1.5 & 0.150 \\
\hline $\mathrm{V}_{\mathrm{PCC}}(\mathrm{V})$ & 48.5 & 49.8 & 49.9 \\
\hline $\mathrm{CUF}(\%)$ & 43 & 11.4 & 7.4 \\
\hline $\mathrm{VUF}(\%)$ & 1.1 & 1.23 & 1.3 \\
\hline $\mathrm{I}_{\mathrm{THD}}(\%)$ & 8.4 & 4.8 & 4.2 \\
\hline $\mathrm{V}_{\mathrm{THD}}(\%)$ & 2.9 & 3.8 & 2.4 \\
\hline
\end{tabular}

The performance comparison from Fig. 19 is summarized in Table III. It can be seen from Table III that the proposed control method improves $\mathrm{I}_{\mathrm{THD}}$ by more than $4 \%$, and $0.6 \%$, and CUF by more than $35 \%$ and $4 \%$ compared to load-only and fixedcapacity neutral-compensation systems respectively.The 3P-4L SVSI with both neutral-current controllers has $\mathrm{I}_{\mathrm{THD}}$ less than 5\%, which meets the IEEE 1547 standard for grid-tied inverters [22]. Additionally, the designed system also maintains the condition of having a voltage-unbalance factor (VUF) of less than 3\% for an average 10-30 minute interval and once in a 1 hour period as can be seen in Table III [25].

In summary, both experimental and simulation results verify that using the proposed control method, the SVSI available capacity can be utilized to provide higher neutral-current compensation and, in turn, better phase balancing. This can solve the higher-capacity-requirement problem for $3 \mathrm{P}-4 \mathrm{~L}$ converters. 


\section{CONCLUSION}

A novel current-control method is presented to minimize the system unbalance from variable loads connected to a low-voltage $3 \mathrm{P}-4 \mathrm{~W}$ distribution network. Both simulation and experimental results prove that the unused SVSI capacity can be utilized with the proposed dynamic capacity allocation method to enhance the unbalance compensation from a 3P-4L SVSI. The SVSI system with the proposed current-control method can provide stable performance with better phase balancing ( $4 \%$ of CUF), and an improvement in THD $(\sim 0.6 \%)$ while operating with active and reactive power regulators, as compared to fixed-capacity SVSIs. Although the experimental results are presented with a constant dc power supply, the designed current controllers are able to provide stable output from actual PV units even with variable solar irradiance. The proposed capacity utilisation method can also be used with residential loads and any 3P-4W LV networks. The future aim of this research is to apply nonlinear controllers to improve the shortcomings from the PI controller and install the SVSI with an actual PV unit to demonstrate the system's performance with the proposed method in a real environment.

$$
\begin{array}{r}
\text { APPENDIX } \\
\frac{i_{p c c-d}}{d_{d}}=V_{d c} \frac{s c_{f} r_{f d}+1}{H_{1}(s)} \\
\frac{i_{v 0}}{d_{0}}=V_{d c} \frac{s^{2} L_{T}^{\prime} C_{f}+S C_{f} r_{f d}+1}{H_{2}(s)}
\end{array}
$$

where $H_{1}(s)=S^{3} C_{f} L_{T} L_{f 1}+S^{2} C_{f}\left[L_{f 1}\left(r_{T}+r_{f d}\right)+L_{T}\left(r_{f}+r_{f d}\right)\right]+$ $+S\left[C_{f}\left(r_{T} r_{f}+r_{T} r_{f d}+r_{f d} r_{f}\right)+\left(L_{f 1}+L_{T}\right)\right]+\left(r_{T}+r_{f}\right)$;

$H_{2}(s)=S^{3} C_{f} L_{T}^{\prime} L_{f}^{\prime}+S^{2} C_{f}\left[L_{f}^{\prime}\left(r_{T}^{\prime}+r_{f d}\right)+L_{T}^{\prime}\left(r_{f}^{\prime}+r_{f d}\right)\right]+S\left[C_{f} r_{T}+\left(L_{f}^{\prime}+\right.\right.$ $\left.\left.L_{T}^{\prime}\right)\right]+\left(r_{T}^{\prime}+r_{f}^{\prime}\right) ;$ and

$L_{f}^{\prime}=L_{f 1}+3 L_{f n}, r_{f}^{\prime}=r_{f}+3 r_{f n}, L_{T}=L_{t 1}+L_{f 2}, L_{T}^{\prime}=L_{t 1}+3 L_{T n}, r_{T}^{\prime}=r_{T}+$ $3 r_{T n}$, and $r_{T}=r^{\prime}{ }_{T} r_{f}^{\prime}+r^{\prime}{ }_{T} r_{f d}+r_{f d} r_{f}^{\prime}$.

For eigenvalue analysis:

$\mathrm{A}=\mathrm{A}_{10 \times 10} ; \mathrm{A}_{11}=-\frac{\mathrm{r}_{\mathrm{f}}+\mathrm{r}_{\mathrm{fd}}}{\mathrm{L}_{\mathrm{f} 1}} ; \mathrm{A}_{12}=\omega_{\mathrm{PCC}} ; \mathrm{A}_{14}=\frac{\mathrm{r}_{\mathrm{fd}}}{\mathrm{L}_{\mathrm{f} 1}} ; \mathrm{A}_{17}=\frac{-1}{\mathrm{~L}_{\mathrm{f}}} ; \mathrm{A}_{110}=\frac{\mathrm{d}_{\mathrm{d}}}{\mathrm{L}_{\mathrm{f} 1}} ;$

$A_{21}=-\omega_{\mathrm{PCC}} ; A_{22}=-\frac{\mathrm{r}_{\mathrm{f}}+\mathrm{r}_{\mathrm{fd}}}{\mathrm{L}_{\mathrm{f} 1}} ; \mathrm{A}_{25}=\frac{\mathrm{r}_{\mathrm{fd}}}{\mathrm{L}_{\mathrm{f} 1}} ; \mathrm{A}_{28}=\frac{-1}{\mathrm{~L}_{\mathrm{f} 1}} ; \mathrm{A}_{210}=\frac{\mathrm{d}_{\mathrm{q}}}{\mathrm{L}_{\mathrm{f} 1}} ;$

$A_{33}=-\frac{\left(\mathrm{r}_{\mathrm{f}}+3 \mathrm{r}_{\mathrm{fn}}\right)+\mathrm{r}_{\mathrm{fd}}}{\mathrm{L}_{\mathrm{f1}}+3 \mathrm{~L}_{\mathrm{fn}}} ; \mathrm{A}_{36}=\frac{\mathrm{r}_{\mathrm{fd}}}{\mathrm{L}_{\mathrm{f} 1}+3 \mathrm{~L}_{\mathrm{fn}}} ; \mathrm{A}_{39}=\frac{-1}{\mathrm{~L}_{\mathrm{f} 1}+3 \mathrm{~L}_{\mathrm{fn}}} ; \mathrm{A}_{310}=\frac{\mathrm{d}_{0}}{\mathrm{~L}_{\mathrm{f1}}+3 \mathrm{~L}_{\mathrm{fn}}} ;$

$\mathrm{A}_{41}=\frac{\mathrm{r}_{\mathrm{fd}}}{\mathrm{L}_{\mathrm{T}}} ; \mathrm{A}_{44}=-\frac{\mathrm{r}_{\mathrm{T}}+\mathrm{r}_{\mathrm{fd}}}{\mathrm{L}_{\mathrm{T}}} ; \mathrm{A}_{45}=\omega_{\mathrm{PCC}} ; \mathrm{A}_{47}=\frac{1}{\mathrm{~L}_{\mathrm{T}}} ;$

$A_{52}=\frac{\mathrm{r}_{\mathrm{fd}}}{\mathrm{L}_{\mathrm{T}}} ; \mathrm{A}_{54}=-\omega_{\mathrm{PCC}} ; \mathrm{A}_{55}=-\frac{\mathrm{rT}_{\mathrm{T}}+\mathrm{r}_{\mathrm{fd}}}{\mathrm{L}_{\mathrm{T}}} ; \mathrm{A}_{58}=\frac{1}{\mathrm{~L}_{\mathrm{T}}} ;$

$A_{63}=\frac{r_{f d}}{L_{T}+3 L_{T n}} ; A_{66}=-\frac{\left(r_{T}+3 r_{T n}\right)+r_{f d}}{L_{T}+3 L_{T n}} ; A_{69}=\frac{1}{L_{T}+3 L_{T n}} ;$

$A_{71}=\frac{1}{C_{\mathrm{f}}} ; A_{74}=\frac{-1}{C_{\mathrm{f}}} ; A_{78}=\omega_{\mathrm{PCC}} ; A_{82}=\frac{1}{\mathrm{C}_{\mathrm{f}}} ; A_{85}=\frac{-1}{\mathrm{C}_{\mathrm{f}}} ; A_{87}=-\omega_{\mathrm{PCC}} ;$

$\mathrm{A}_{93}=\frac{1}{\mathrm{C}_{\mathrm{f}}} ; \mathrm{A}_{96}=\frac{-1}{\mathrm{C}_{\mathrm{f}}} ; \mathrm{A}_{101}=\frac{-\mathrm{d}_{\mathrm{d}}}{\mathrm{C}_{\mathrm{dc}}} ; \mathrm{A}_{102}=\frac{-\mathrm{d}_{\mathrm{q}}}{\mathrm{C}_{\mathrm{dc}}} ; \mathrm{A}_{103}=\frac{-\mathrm{d}_{0}}{\mathrm{C}_{\mathrm{dc}}} ;$

$B=B_{6 \times 10} ; B_{11}=\frac{V_{d c}}{L_{f 1}} ; B_{22}=\frac{V_{d c}}{L_{f 1}} ; B_{33}=\frac{V_{d c}}{L_{f 1}+3 L_{f n}} ; B_{44}=\frac{-1}{L_{T}} ; B_{55}=\frac{-1}{L_{T}} ;$

$B_{66}=\frac{-1}{L_{T}+3 L_{T n}} ; B_{101}=-\frac{i_{V d}}{C_{d c}} ; B_{102}=-\frac{i_{V q}}{C_{d c}} ; B_{103}=-\frac{i_{V 0}}{C_{d c}}$

$C=C_{10 \times 4} ; C_{14}=C_{25}=C_{36}=C_{410}=1 ; D=0$

PV-SVSI Simulation : Dc capacitor: $3000 \mu \mathrm{F}, \mathrm{f}_{\mathrm{s}}: 3.5 \mathrm{kHz}$, time step: $5 \mathrm{~ms}$, PI controller gains: $\mathrm{Kp}_{1}-\mathrm{Vdc}_{\mathrm{dc}}=2, \mathrm{~T}_{\mathrm{i} 1-\mathrm{Vdc}}=0.005, \mathrm{~K}_{\mathrm{p} 2-\mathrm{VPCC}-\mathrm{d}}=2, \mathrm{~T}_{\mathrm{i} 2-\mathrm{VPCC}-\mathrm{d}}=0.5, \mathrm{~K}_{\mathrm{p} 3}$ ${ }_{\mathrm{Idq}}=8, \mathrm{~T}_{\mathrm{i} 3-\mathrm{Idq}}=0.003, \mathrm{~K}_{\mathrm{p} 4-\mathrm{ON}}=15, \mathrm{~T}_{\mathrm{i} 4-\mathrm{N}}=0.5, \mathbf{L C L}$ filter: $\mathrm{L}_{\mathrm{fl}(\mathrm{a}, \mathrm{b}, \mathrm{c}, \mathrm{n})}=4 \mathrm{mH} ; \mathrm{C}_{\mathrm{f}}=$ $\left.10 \mu \mathrm{F} ; \mathrm{L}_{\mathrm{f} 2(\mathrm{a}, \mathrm{b}, \mathrm{c})}=1 \mathrm{mH} ; \mathrm{r}_{\mathrm{a}, \mathrm{b}, \mathrm{c}, \mathrm{n}}\right)=1 \mathrm{~m} \Omega, \mathrm{Rf}_{\mathrm{d}}=3 \mathrm{~m} \Omega, \mathbf{L V}$ Grid: $33 / 11 \mathrm{kV} / 420 \mathrm{~V}$, DT rating: $500 \mathrm{kVA}, \mathrm{X}_{\mathrm{L}} .04$ p.u., $\mathrm{R}_{\mathrm{GND}}(3 \mathrm{P}): 10 \Omega, \mathrm{R}_{\mathrm{DT}-\mathrm{GND}}=1 \Omega$.

TABLE A-I: Different R/X values of different transmission cables

\begin{tabular}{|c|c|c|c|c|c|}
\hline Cable no. & Name & $\mathrm{R}_{+}$ & $\mathrm{X}_{+}$ & $\mathrm{R}_{0}$ & $\mathrm{X}_{0}$ \\
\hline 1 & MOON 7/4.75AAC & 0.265 & 0.33 & 0.5 & 1.01 \\
\hline 2 & $7 / .080-\mathrm{Cu}(7 / 14)$ & 0.89 & 0.38 & 1.28 & 1.34 \\
\hline
\end{tabular}

TABLE A-II: Description of experimental components

\begin{tabular}{|c|c|}
\hline Component name & Specifications \\
\hline Dc voltage source (Sorensen) & $0-300 \mathrm{~V}, 2.8 \mathrm{~A}, 850 \mathrm{~W}$ \\
\hline Four-leg inverter (Semiteach) & $750 \mathrm{~V}_{\mathrm{dc}}, 400 \mathrm{~V}_{\mathrm{ac}}, 30 \mathrm{~A}, 50 \mathrm{~Hz}$ \\
\hline Dc link capacitor & $1100 \mu \mathrm{F}$ \\
\hline Filter inductors $\left(\mathrm{L}_{\mathrm{f} 1}\right.$ and $\left.\mathrm{L}_{\mathrm{f} 2}\right)$ & $1.4 \mathrm{mH}$ and $120 \mu \mathrm{H}, 10 \mathrm{~A}$ \\
\hline Filter capacitors & Film capacitors, $10 \mu \mathrm{F}$ \\
\hline
\end{tabular}

\begin{tabular}{|c|c|}
\hline Ac circuit breaker & $40 \mathrm{~A}$, and residual current of $30 \mathrm{~mA}$ \\
\hline Programmable loads & $3.6 \mathrm{~kW}, 36 \mathrm{~A}, 350 \mathrm{~V}_{\mathrm{ac}}$ \\
\hline Grid supply & $3 \mathrm{P}-5$ pin outlet, $500 \mathrm{~V}_{\mathrm{ac}}, 20 \mathrm{~A}$ \\
\hline Variable transformer & $8.14 \mathrm{kVA}, 415 \mathrm{~V}, 10 \mathrm{~A} / \mathrm{ph}$ ase \\
\hline Hall-effect transducers (I and V) & $\pm 30 \mathrm{~A},+1000 \mathrm{~V}$ \\
\hline
\end{tabular}

\section{REFERENCES}

[1] L. S. Czarnecki and P. M. Haley, "Unbalanced power in four-wire systems and its reactive compensation," IEEE Trans. Power Deliv., vol. 30, no. 1, pp. $53-63,2015$.

[2] D. Sreenivasarao, P. Agarwal, and B. Das, "Neutral current compensation in three-phase, four-wire systems: A review," Elect. Power Syst. Res., vol. 86, pp. 170-180, May 2012.

[3] K. W. Park, H. C. Seo, C. H. Kim, C. S. Jung, Y. P. Yoo, and Y. H. Lim, "Analysis of the neutral current for two-step-type poles in distribution lines," IEEE Trans. Power Del., vol. 24, no. 3. pp. 1483-1489, 2009.

[4] S. Patel and L. Hmurcik, "Preventable Ground Wire Accidents And Fires," IEEE International Conference on Environment and Electrical Engineering, pp. 1-5, Italy, 2016.

[5] B. Singh, P. Jayaprakash, and D. P. Kothari, "Magnetics for neutral current compensation in three-phase four-wire distribution system," Int. Conf. Power Electron. Drives Energy Syst., vol. 670563, India, 2010.

[6] A. S. D. Morais, F. L. Tofoli, and I. Barbi, "Modeling, digital control, and implementation of a three-phase four-wire power converter used as a power redistribution device," IEEE Trans. Ind. Informatics, vol. 12, no. 3, pp. 1035-1042, 2016.

[7] S. Inoue, T. Shimizu, and K. Wada, "Control methods and compensation characteristics of a series active filter for a neutral conductor," IEEE Trans. Ind. Electron., vol. 54, no. 1, pp. 433-440, 2007.

[8] M. Aredes, J. Hafner, and K. Heumann, "Three-phase four-wire shunt active filter control strategies," IEEE Trans. Power Electron., vol. 12, no. 2. pp. 311-318, 1997.

[9] C. L. Chen and C. E. Lin, "An active filter for an unbalanced three-phase system using the synchronous detection method," Electr. Power Syst. Res., vol. 36, no. 3, pp. 157-161, 1996.

[10] F. H. M. Rafi, M. J. Hossain, and J. Lu, "Improved neutral current compensation with a four-leg PV smart VSI in a LV residential network," IEEE Trans. Power Deliv., vol. 31, no. 5, pp. 2291-2302, 2017.

[11] M. Pattnaik and D. Kastha, "Harmonic Compensation With Zero-Sequence Load Voltage Control in a Speed-Sensorless DFIG-Based," IEEE Trans. Ind. Electron., vol. 60, no. 12, pp. 5506-5514, 2013.

[12] C. B. Mellado, C. H. Cariman, R. Cardenas et. al., "Experimental Evaluation of a CPT-Based Distributed Generation," IEEE Journal of Emerging and Selected Topics in Power Electronics, vol. 5, no. 2, pp. 747759,2017

[13] A. S. Bubshait, A. Mortezaei, M. Simoes, and T. Busarello, "Power Quality Enhancement for a Grid Connected Wind Turbine Energy System," IEEE Trans. Ind. Appl., vol. 53 , no. 3, pp. 2495-2505, 2017.

[14] X. Guo, R. He, J. Jian, Z. Lu, X. Sun, and J. M. Guerrero, "Leakage current elimination of four-leg inverter for transformerless three-phase PV systems," IEEE Trans. Power Electron., vol. 31, no. 3, pp. 1841-1846, 2016.

[15] F. H. M. Rafi, M. J. Hossain, D. Leskarac, and J. Lu, "Reactive power management of a AC/DC microgrid system using a smart PV inverter," Power \& Energy Society General Meeting, 2015 IEEE. pp. 1-5, 2015.

[16] N. R. Merritt, C. Chakraborty, and P. Bajpai, "New Voltage Control Strategies for VSC-Based DG Units in an Unbalanced Microgrid," IEEE Trans. Sustain. Energy, vol. 8, no. 3, pp. 1127-1139, July, 2017.

[17] R. A. Ramos and R. Reginatto, "On electrical power evaluation in dq coordinates under sinusoidal unbalanced conditions," IET Gener. Transm. Distrib., vol. 8, no. 5, pp. 976-982, 2014.

[18] M. N. Kabir, Y. Mishra, G. Ledwich, Z. Y. Dong, and K. P. Wong, "Coordinated control of grid-connected photovoltaic reactive power and battery energy storage systems to improve the voltage profile of a residential distribution feeder," IEEE Trans. Ind. Informat., vol. 10, no. 2. pp. 967-977, 2014.

[19] F. H. M. Rafi, M. J. Hossain, and J. Lu, "Hierarchical controls selection based on PV penetrations for voltage rise mitigation in a LV distribution network," Int. J. Electr. Power Energy Syst., vol. 81, pp. 123-139, 2016.

[20] X. Wang, F. Zhuo, J. Li, L. Wang, and S. Ni, "Modeling and control of dual-stage high-power multifunctional PV system in d-q-o-Coordinate," IEEE Trans. Ind. Electron., vol. 60, no. 4, pp. 1556-1570, 2013.

[21] M. J. Hossain, M. A. Mahmud, H. R. Pota, and N. Mithulananthan, "Design of non-interacting controllers for PV systems in distribution networks," IEEE Trans. Power Syst., vol. 29, no. 6, pp. 2763-2774, 2014. 
[22] http://grouper.ieee.org/groups/scc21/1547/1547_index.html, IEEE 1547 Standard for Interconnecting Distributed Resources with Electric Power Systems.

[23] http://shop.semikron.com/en/Products-and-Shop/ProductGroups/STACKs/SEMITEACH/SEMITEACH-B6U-E1CIF-B6CI.html

[24] http://www.denki.com.au/SwitchGearModule.html

[25] National Electricity Code, V. 1, Queensland technical derogation, 2002. 